\title{
Tension-Bearing Couples (TBC), Part II* : Adding Realism to the FEM Validation of Proposed Analysis Approach
}

\author{
Hatem H. Daken ${ }^{\dagger}$ and M. Kamal Shoukry ${ }^{\ddagger}$
}

\begin{abstract}
This article discusses the results of seven (7) fastener joints analyzed using the enhanced analysis approach proposed in Reference 2 as compared to the results of finite element models that were constructed to simulate the actual properties and behavior of these joints. These finite element models, unlike the idealized ones of Reference 2, permit flexural and shear deformations in the joint plates. Results of the proposed enhanced analysis approach differ significantly from the results of the realistic FEM models. The difference is approximately between $+20 \%$ and $-80 \%$. Results of the realistic FEM models also indicate that the moment induced tensile load is carried mainly by the fasteners at the fitting's free edges being pulled up by the out-of-plane bending moment. A probability distribution of fastener maximum load correction factors is established for use with the proposed enhanced analysis approach.
\end{abstract}

Keywords: Tension-Bearing Couple, Tensile-Loaded Fasteners, Bolted Joints, Fastener Joints, Finite Element Method, Finite Element Analysis, Finite Element Modeling

\section{Introduction}

The validation and evaluation of the new analysis approach ${ }^{1}$ is introduced in Reference 2 . This article addresses the effects of permitting flexural and shear deformations in the upper plate of the finite element models on the validation results discussed in the above reference ${ }^{2}$.

This article entails seven (7) of the fastener joints described in Reference 2 and illustrated in Figure 1 and Figure 2 of this reference, excluding joint 4x4A. The materials selected for use in the proposed enhanced analysis approach are: 7050-T74 aluminum die forging per AMS 4107, with extensional/compressive modulus of elasticity of $10.7 \times 10^{6} \mathrm{psi}$, for the fitting, $6 \mathrm{Al}$ $4 \mathrm{~V}$ titanium alloy per AMS 4965, with extensional modulus of elasticity of $16.0 \times 10^{6} \mathrm{psi}$, for the fasteners. No material needs to be selected for the substrate/base because the proposed enhanced analysis approach assumes all extensional deformations to occur in the fasteners and all compressive deformations to occur in the fitting.

\section{Finite Element Modeling}

Autodesk $^{\mathrm{TM}}$ Algor $^{\mathrm{TM}}$ Simulation 2010 was used to construct finite element models that simulate the properties and behavior of the fastener joints under investigation. All components of the fastener joints are modeled using isotropic 8-node brick elements with compatibility enforced. An approximate absolute mesh size of 0.065 ” is used for all joint

\footnotetext{
* Refer to the other two parts in this volume

${ }^{\dagger}$ Ph.D., Senior Structural Analysis Scientist/Engineer, Boeing Commercial Airplanes, The Boeing Company, Seattle, WA, USA, hatemdaken@aol.com

$\ddagger$ Ph.D., Professor of Design and Production Engineering, German University, Cairo, Egypt
} 
components. Enforced boundary conditions are such that all six degrees of freedom are constrained at the lower surface/plane of the substrate/base while only five degrees of freedom are constrained at the lower fastener heads. Translation along the z-axis direction is unconstrained for all fasteners. Surface contact pairs are established between the upper fastener heads and the upper surface/plane of the fitting, the lower surface/plane of the fitting and the upper surface/plane of the substrate/base, and the lower surface/plane of the substrate/base and the lower fastener heads. The details of the finite element models are described and depicted in Reference 2.

The proposed enhanced analysis approach idealizes the fitting as a plate of infinite flexural and shear stiffness supported by tension springs in the tension region and a compression spring in the bearing region. These springs rest on a foundation of infinite extensionalcompressive stiffness. It also assumes that extensional deformations are allowed only in the fasteners while compressive deformations are allowed only in the bearing side of the fitting. The realistic FEM models, on the other hand, assume the fitting as a plate of finite flexural and shear stiffness supported by tension springs in the tension region and a compression spring in the bearing region. These springs rest on a foundation of infinite extensionalcompressive stiffness. This simply means that flexural, shear, and extensional-compressive deformations are allowed everywhere within the model except the substrate/base.

The fitting material is 7050-T74 aluminum die forging per AMS 4107, with extensional/compressive modulus of elasticity of $10.7 \times 10^{6}$ psi, the fasteners are $6 \mathrm{Al}-4 \mathrm{~V}$ titanium alloy per AMS 4965, with extensional modulus of elasticity of $16.0 \times 10^{6} \mathrm{psi}$, and the substrate/base material is a fictitious material based on AISI 4130 low-alloy steel per AMS 6350 , with extensional modulus of elasticity of $29.0 \times 10^{12}$ psi.

The proposed enhanced analysis approach and FEM analysis are performed according to the validation roadmap depicted in Figure 9 of reference 2. The analyzed joints are loaded in the realistic FEM models as described and shown in Figure 5 of same reference.

\section{Validation Results, Comparisons, and Discussions}

The ratio of the modulus of elasticity of the fasteners to that of the fitting in Reference 2 is $\left(16.0 \times 106 / 29.0 \times 10^{12}\right)$ or 0.000001 . This is intended mainly to prevent flexural and shear deformations in the idealized FEM models. In the current study this ratio is $\left(16.0 \times 10^{6} / 10.7 \times 10^{6}\right)$ or 1.495327 , which is intended mainly to permit flexural and shear deformations in the realistic FEM models. The impact of the difference between these two ratios is depicted in Figure 1. This figure represents the $8 \mathrm{x} 2$ joint loaded by an out-of-plane bending moment that makes zero degree angle with respect to the local $\mathrm{x}$-axis. The upper part is the result of the idealized FEM model and the lower part is the result of the realistic FEM model. The reason for these two significantly different results is the difference between the moduli of elasticity ratios of the fasteners and fitting in the idealized and realistic FEM models, i.e. 0.000001 and 1.495327 .

To demonstrate the impact of permitting flexural and shear deformations, in the realistic FEM models, on the general deformation pattern of the fitting, Figure 2 illustrates a $6 \times 4$ joint loaded by an out-of-plane bending moment that makes a $60^{\circ}$ angle with to the local $\mathrm{x}$-axis.

The results of the realistic FEM models demonstrate, and contrary to the idealized FEM models, that:

o Equations 1 through 11 of Reference 1 and equations 1 through 8 of Reference 2 are 
valid only for the proposed enhanced analysis approach and idealized FEM models. They do not apply for the realistic FEM models

o The realistic FEM models do not result in any zero-load fasteners, as illustrated in Figure 1

o There are regions of separation, or no contact, between the fitting and the substrate/base as depicted in Figure 1

o The bearing area of the fitting is not localized to one region and does not have regular shapes as the proposed enhanced analysis approach and idealized FEM models assume, Figure 3

o Flexural and shear deformations exhibit a high gradient and localized pattern near the free edges of the fitting that the out-of-plane bending moment tries to pull up. This is demonstrated by the patterns and magnitudes of the Z-displacement contours depicted in Figure 4 through Figure 10

The maximum and total fastener loads computed by the proposed enhanced analysis approach were compared with their counterparts resulting from the realistic FEM models for every joint and out-of-plane bending moment angle. The results are depicted in Figure 11 and Figure 12. The differences are significant and approximately range from $+20 \%$ to $-80 \%$. When these parameters were compared to the results of the idealized FEM models the differences were only $\pm 10 \%$. This is mainly because both the proposed enhanced analysis approach and the idealized FEM models do not account for flexural and shear deformations in the fitting. These significant differences do not kill the proposed enhanced analysis approach altogether. The introduction of correction factors for the results of the proposed enhanced analysis approach can solve this problem.

The correction factors for the total and maximum fastener load are depicted in Figure 13 and Figure 14. A correction factor is simply the ratio of the result of realistic FEM model divided by the respective proposed enhanced analysis approach result. StatSoft's ${ }^{\circledR}$ STATISTICA 9.0.231.9 was utilized to create the normal probability plot for the fastener maximum load correction factors. This analysis entails correction factors for all joints and all applied out-ofplane bending moment angles. The resulting probability plot is depicted in Figure 15 . The abscissa of this figure represents observed values of fastener maximum load correction factors and the ordinate represents expected normal values, which are expressed in terms of a normal distribution standard deviation multiplier.

STATISTICA was also used to create observed and expected normal probability and cumulative probability for the fastener maximum load correction factors. This analysis also entails correction factors for all joints and all applied out-of-plane bending moment angles and is depicted in Figure 16.

As part of the previous analysis, STATISTICA performed a chi-square test to evaluate the goodness of fit of the fastener maximum load correction factors to a normal distribution. The parameters of this chi-square test are:

o Number of categories is 11 ,

o Lower limit is 0.6 ,

o Upper limit is 3.8,

o The mean is 2.0656303, and

o The variance is 0.41404005 . 
As a background, the chi-square test is used to determine whether there is a significant difference between the expected and observed frequencies in one or more categories ${ }^{3}$. This test resulted in:

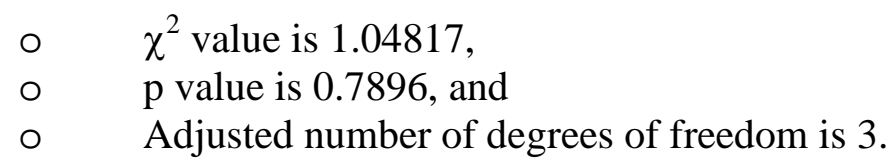

This means that there is a $78.96 \%$ probability that the difference between expected and observed values is due to chance alone and accordingly we cannot reject the null hypothesis.

The upper bound of the fastener maximum load correction factors (FMLCF) is depicted in Figure 14 versus the angle of applied out-of-plane bending moment with respect to the local $x$-axis. Maximum values occur at $\alpha=0^{\circ}$ and $\alpha=90^{\circ}$ while the minimum value occurs at $\alpha=45^{\circ}$. Based on this fact, once the FMLCF is determined from Figure 16, per our preference of confidence level, the fastener maximum load correction factor can be determined for any angle of the applied out-of-plane bending moment using:

$\operatorname{FMLCF}(p, \alpha)=\operatorname{FMLCF}(p)-\operatorname{AngFac} \cdot \sin (2 \cdot \alpha)$, where:

$\operatorname{FMLCF}(p, \alpha) \quad$ Fastener maximum load correction factor as function of the angle of applied out-of-plane bending moment with respect to the local $\mathrm{x}$-axis and selected confidence level

FMLCF(p) Fastener maximum load correction factor as of function of selected confidence level, from Figure 16

AngFac Factor to account for the angle of the applied out-of-plane bending moment vector with respect to the local $\mathrm{x}$-axis

$\alpha$

Angle of applied out-of-plane bending moment with respect to the local $\mathrm{x}$-axis

An added merit for using the enhanced analysis approach is depicted in Figure 17. As illustrated, the processing times for the finite element models are extremely higher than the processing time for the proposed enhanced analysis approach. The processing times for the finite element models are based on using Dell Precision Mobile Workstation M6300 with Intel Core 2 Duo CPU T9300 @ 2.50 GHz and 8 GB of 2.49 GHz RAM and Autodesk Algor Simulation 2010 iterative AGM solver. The proposed enhanced analysis approach processing time is less than one (1) minute for any analyzed joint or moment angle.

\section{Conclusions}

The results of the realistic FEM models are significantly different from the results of proposed enhanced analysis approach. Percentage differences between results of the proposed enhanced analysis approach and results of the realistic FEM models approximately range from +20 to $-80 \%$ for the highest fastener tensile load and $+20 \%$ to $-30 \%$ for the total tensile load of all fasteners across all joints analyzed. These differences are attributed to: 1) allowing flexural and shear deformations of the fitting in the realistic FEM models; 2) the fastener flexural and shear deformations, particularly in the direction of the shorter dimension of the fitting; and 3) bearing area of the fitting is not localized to one region and does not have regular shapes as the proposed enhanced analysis approach and idealized FEM models assume. 
The correction factors determined in this study are based on fastener/fitting modulus of elasticity ratios of 0.000001 , representing the proposed enhanced analysis approach and idealized FEM models, and 1.495327, representing the realistic FEM models. The estimated correction factor is assumed to be 1.0 for the first and approximately 3.80 for the second. Our next task is to determine correction factors for different fastener/fitting combinations that entail: aluminum/steel, modulus of elasticity ratio of 0.362 ; titanium/steel, modulus of elasticity ratio of 0.583; aluminum/titanium, modulus of elasticity ratio of 0.656; titanium/titanium, modulus of elasticity ratio of 1.056; titanium/aluminum, modulus of elasticity ratio of 1.495, steel/titanium, modulus of elasticity ratio of 1.813; and steel/aluminum, modulus of elasticity ratio of 2.843 . We believe these combinations represent every possible fastener/fitting combination from an engineering perspective. This would enable us to develop a chart for correction factors versus the fastener/fitting modulus of elasticity ratio to be used with the proposed enhanced analysis approach. The true potential of the TBC proposed enhanced analysis approach can only be evaluated after such work is complete.

\section{Acknowledgement}

The authors wish to acknowledge with sincere thanks the help and cooperation of Mr. Edward Simmons and Mr. Rajesh Radhakrishnan of Autodesk Inc. Mr. Simmons helped us to acquire the Algor software package at an appealing discounted price and Mr. Radhakrishnan provided us with technical support, help, and guidance throughout the finite element analysis phase of this effort. Without their unfailing assistance and support the completion of this work was highly doubtful.

\section{References}

[1] Daken, Hatem H., "Tension-Bearing Couples (TBC): An Analysis Approach for Fastener Joints Loaded By Out-Of-Plane Forces and Compound Bending Moments," 13th International Conference on Aerospace Sciences \& Aviation Technology, ASAT13, May $26-28,2009$

[2] Daken, Hatem H. and Shoukry, M. Kamal, “Tension-Bearing Couples (TBC), Part I: FEM Validation of Proposed Analysis Approach, Approach Enhancement, Results Comparisons and Evaluation,” 14th International Conference on Aerospace Sciences \& Aviation Technology, ASAT- 14, May 24 - 26, 2011

[3] Maben, Anne F., "CHI-SQUARE TEST - Adapted by from "Statistics for the Social Sciences" by Vicki Sharp,” http://www.enviroliteracy.org/pdf/materials/1210.pdf 


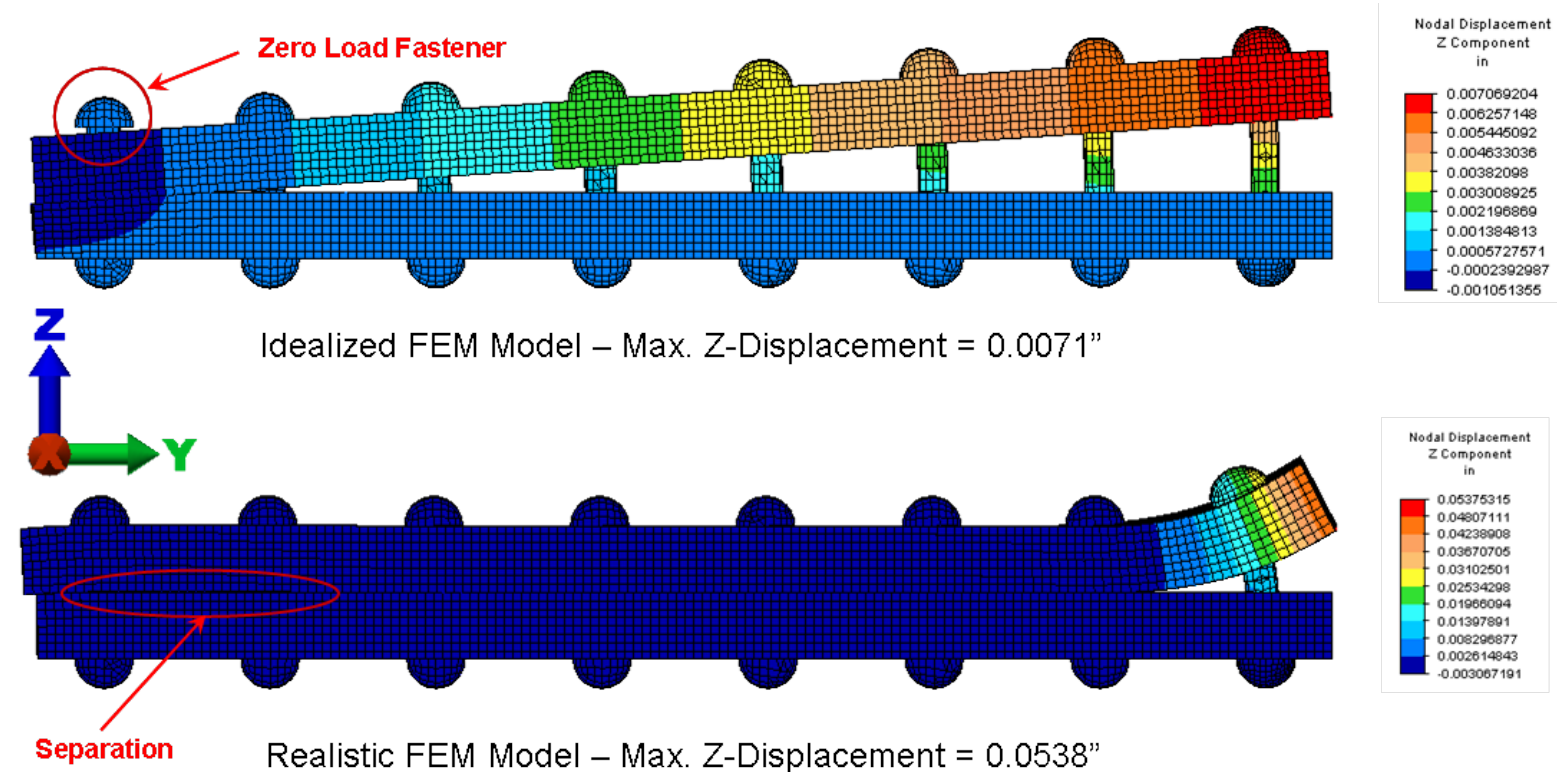

Figure 1: The Deformation Patterns of Idealized and Realistic FEM Models for the 8x2 Joint Loaded with a $0^{\circ}$ Bending Moment

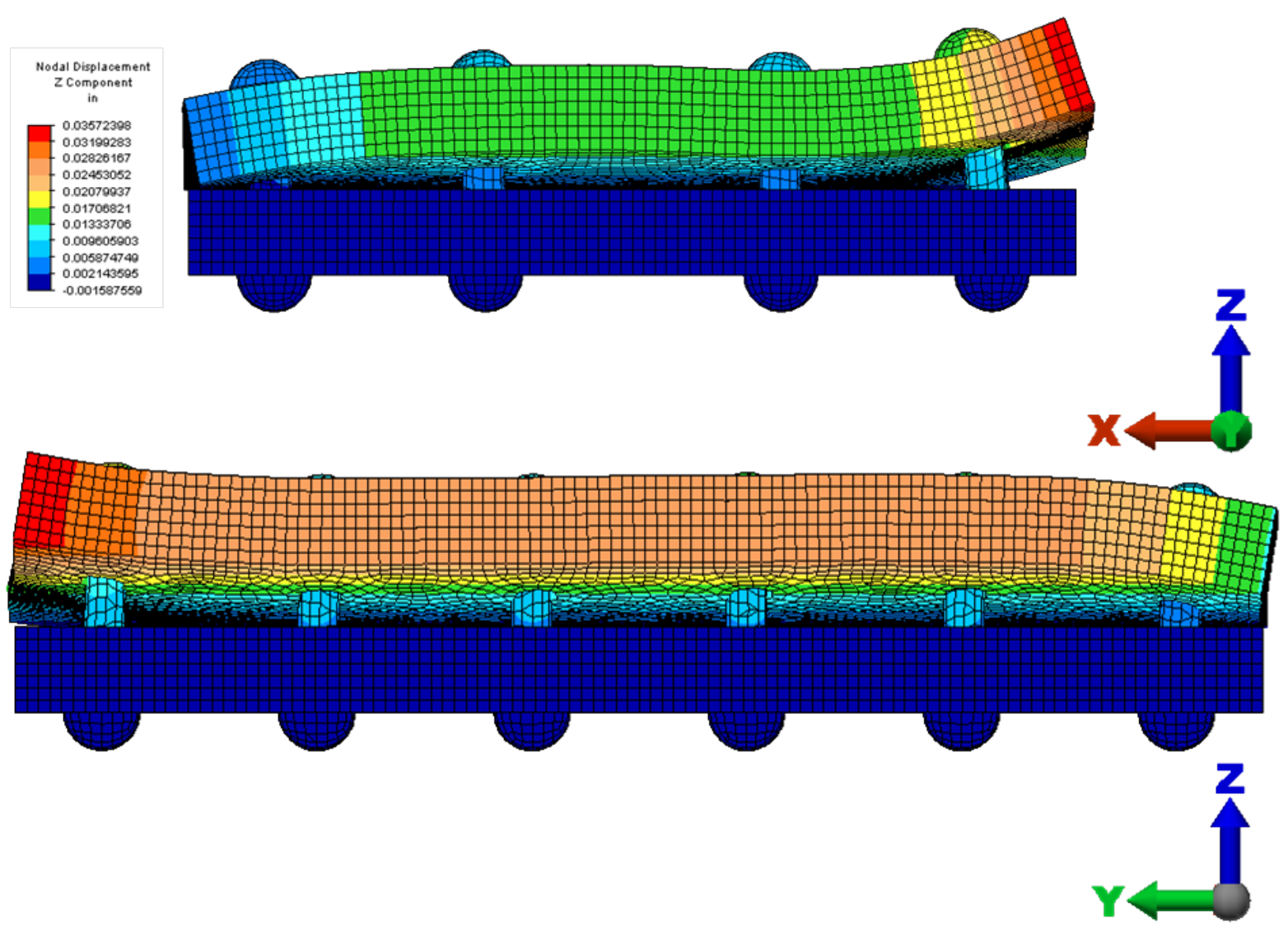

Figure 2: Deformation Pattern of a Realistic FEM Model for the 6x4 Joint Loaded with a $60^{\circ}$ Bending Moment 


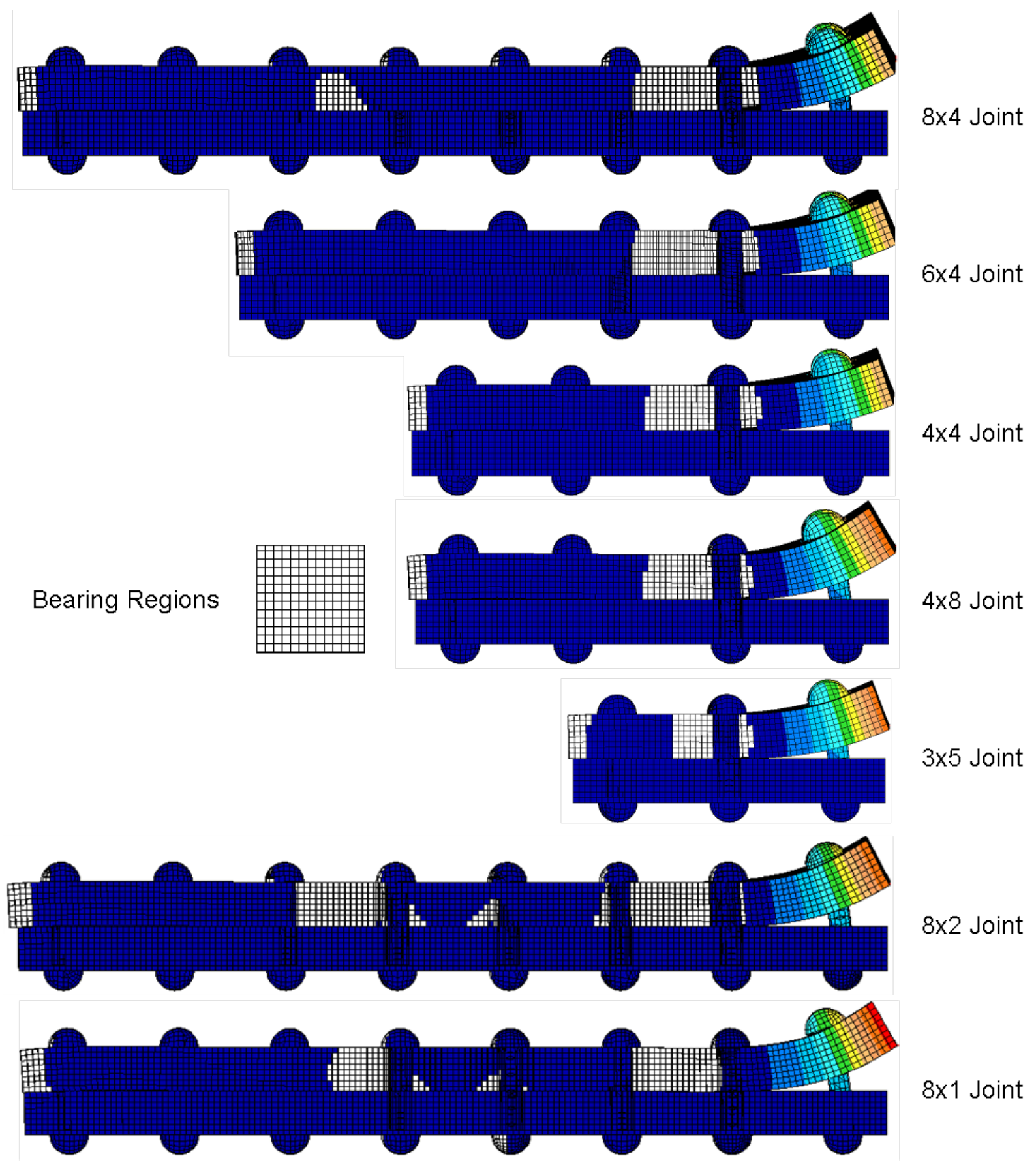

Figure 3: Bearing Regions of the Realistic FEM Models 


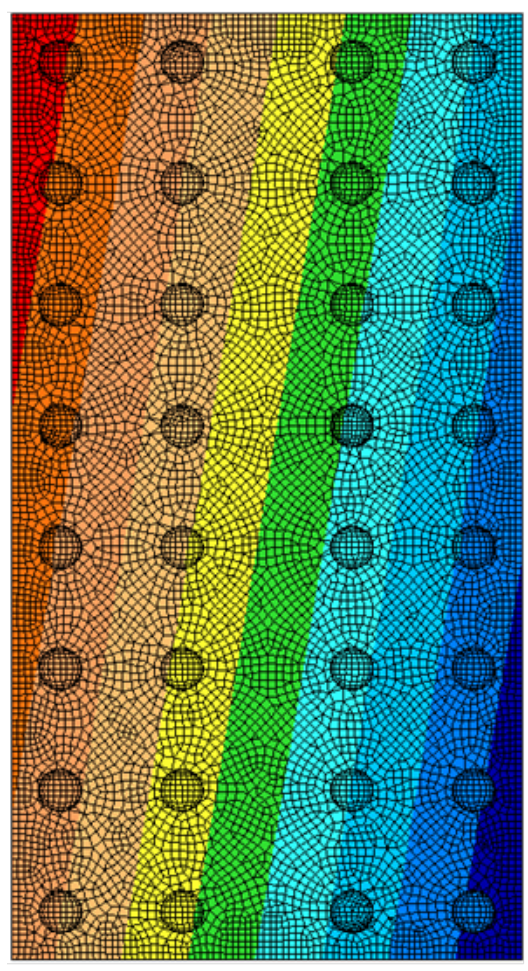

Idealized FEM Model

Max. Z-Displ. $=0.0072 "$
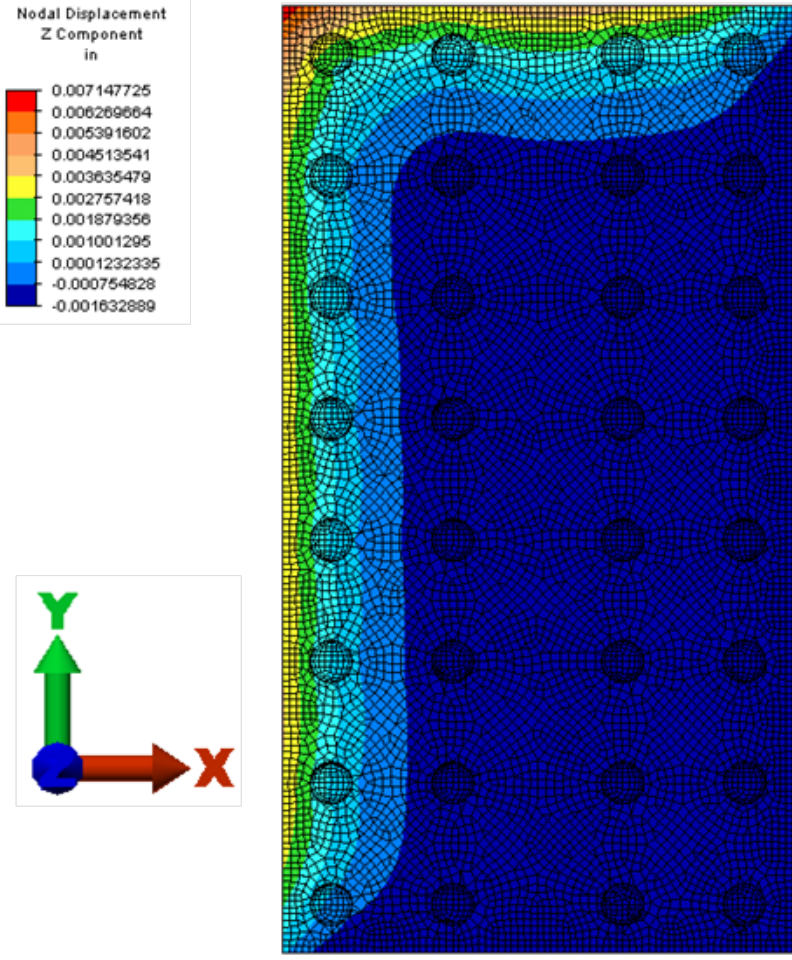

Nodal Displacement $\mathrm{Z}$ Componen
in

0.0379891

(1)

0.03403034
-0.03007148

0.03007149
-0.02611264

0.02215379

$-0.01810494$

0.01423609

0.006318392

0.002350542
-0.001599308

Realistic FEM Model

Max. Z-Displ. $=0.0380^{\prime}$

Figure 4: Comparison between the Z-Displacement Contours of Idealized and Realistic FEM Models - 8x4 Joint Loaded with a $45^{\circ}$ Bending Moment

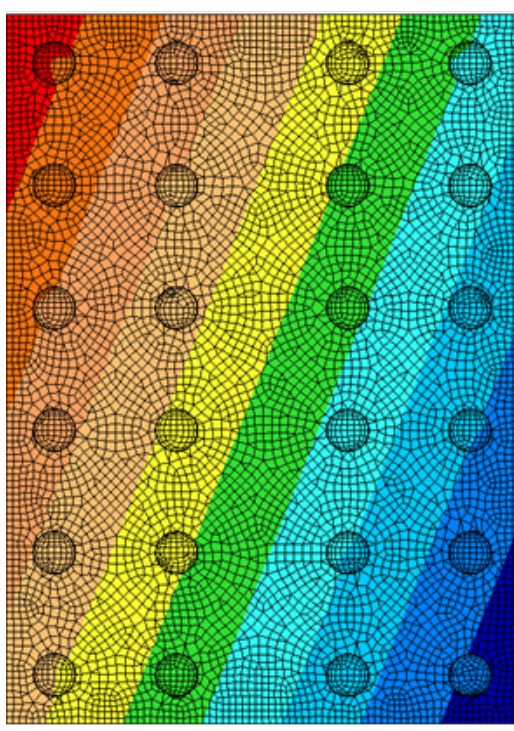

Idealized FEM Model Max. Z-Displ. $=0.0082$
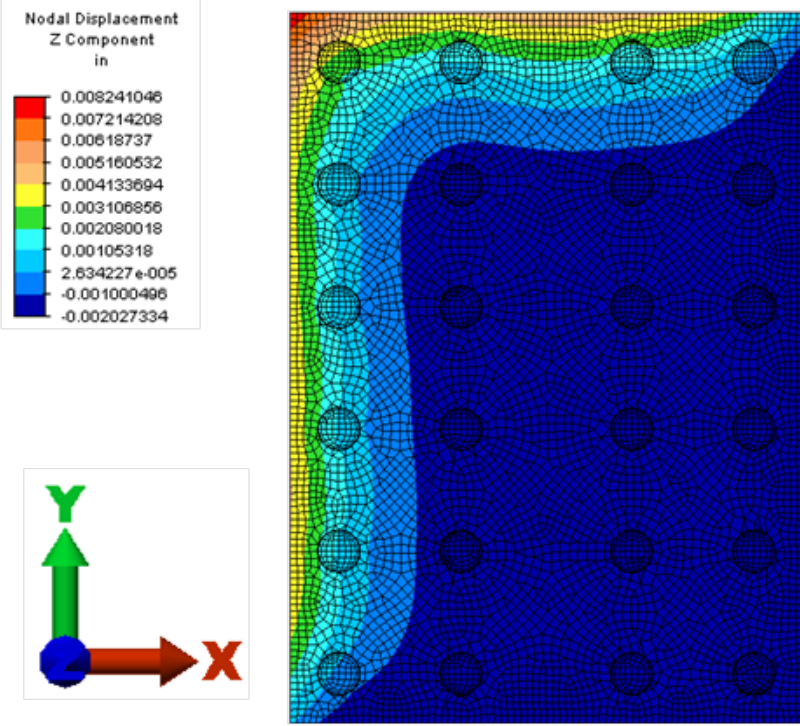

Nodal Displacement $z$ Component

0.03912630 0.03504099 0.03097357 $-0.02689715$ 0.02282074 0.01874433 0.01406791 - 0.006515088 0.006515088 .0 .001637738

Realistic FEM Model Max. Z-Displ. $=0.0391 "$

Figure 5: Comparison between the Z-Displacement Contours of Idealized and Realistic FEM Models - 6x4 Joint Loaded with a $45^{\circ}$ Bending Moment 


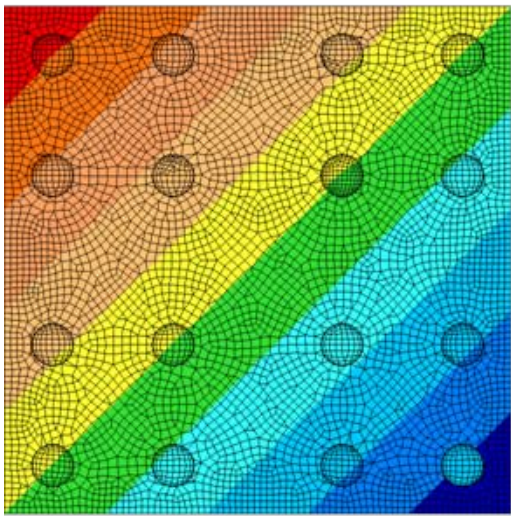

Idealized FEM Model Max. Z-Displ. $=0.0085$ "

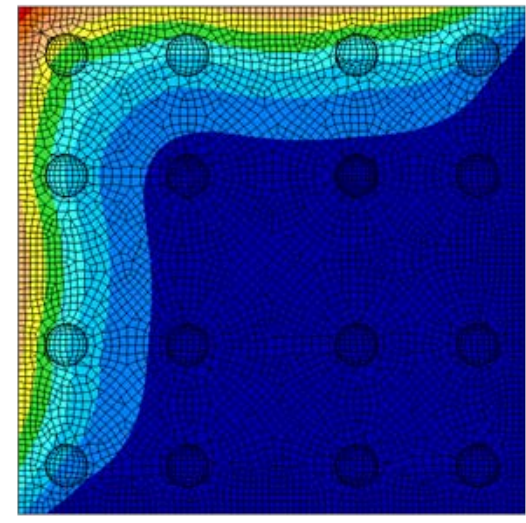

Nodal Displacement $z$ Component 0.03382053 $-0.03011539$ 0.0266102 $-0.02310511$ $-0.01950997$ 0.01800482 0.01258968 0.00908454 0.002074250 02014250

Realistic FEM Model

Max. Z-Displ. $=0.0336^{\prime \prime}$

Figure 6: Comparison between the Z-Displacement Contours of Idealized and Realistic FEM Models - 4x4 Joint Loaded with a $45^{\circ}$ Bending Moment
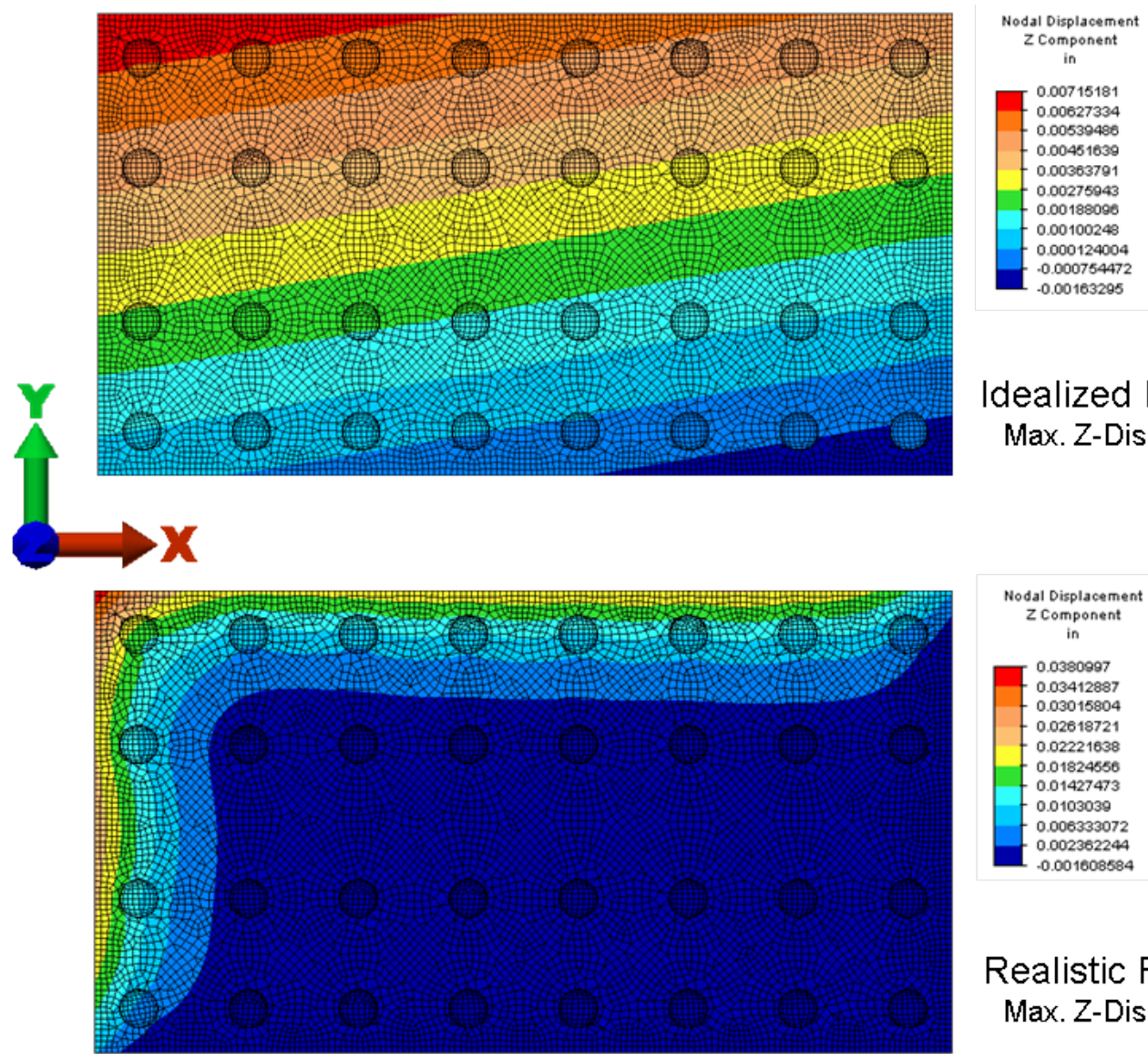

Idealized FEM Model Max. Z-Displ. $=0.0072$

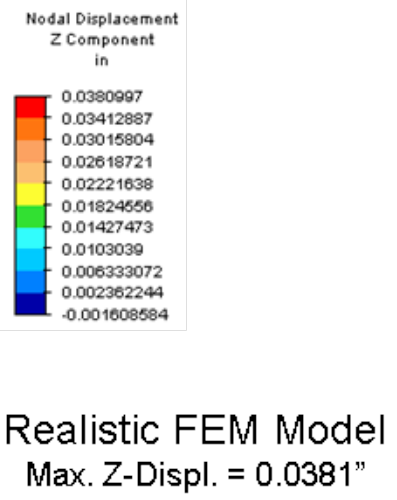

Figure 7: Comparison between the Z-Displacement Contours of Idealized and Realistic FEM Models - 4x8 Joint Loaded with a $45^{\circ}$ Bending Moment 
Idealized FEM Model

Max. Z-Displ. $=0.0079 "$

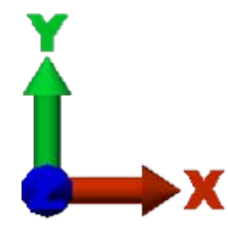

Realistic FEM Model Max. Z-Displ. $=0.0305 "$

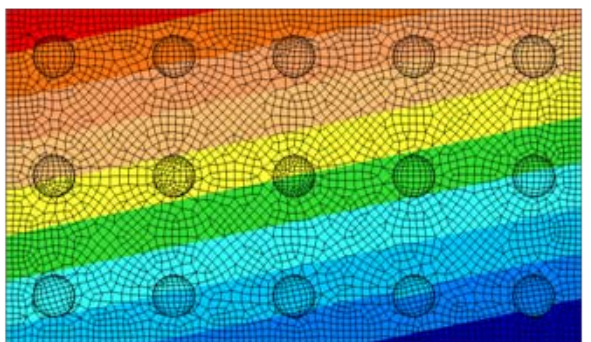

Nodal Displacement $z$ Component
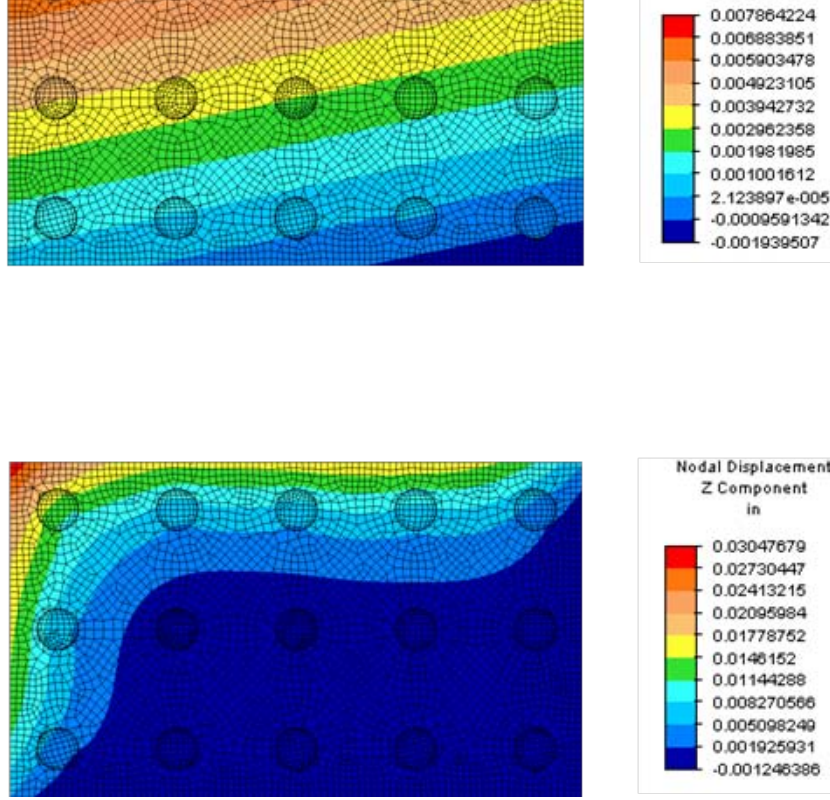

Nodal Displacement $z$ Component

0.0304767 0.0273044 0.02413215 0.0209598 0.01778752 0.0140152 0.01144288 0.008270566 0.005098240 0.001925931 0.001246386

Figure 8: Comparison between the Z-Displacement Contours of Idealized and Realistic FEM Models - 3x5 Joint Loaded with a $45^{\circ}$ Bending Moment

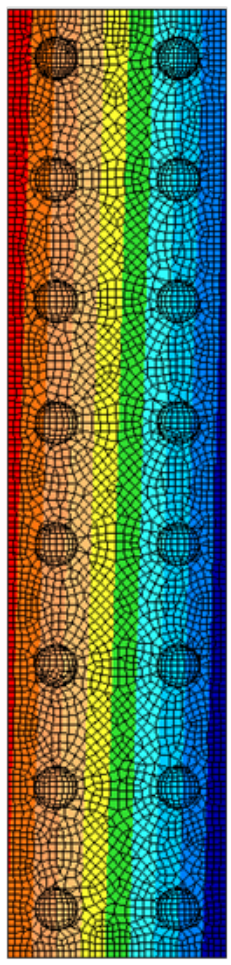

Idealized FEM Model Max. Z-Displ. $=0.0069 "$
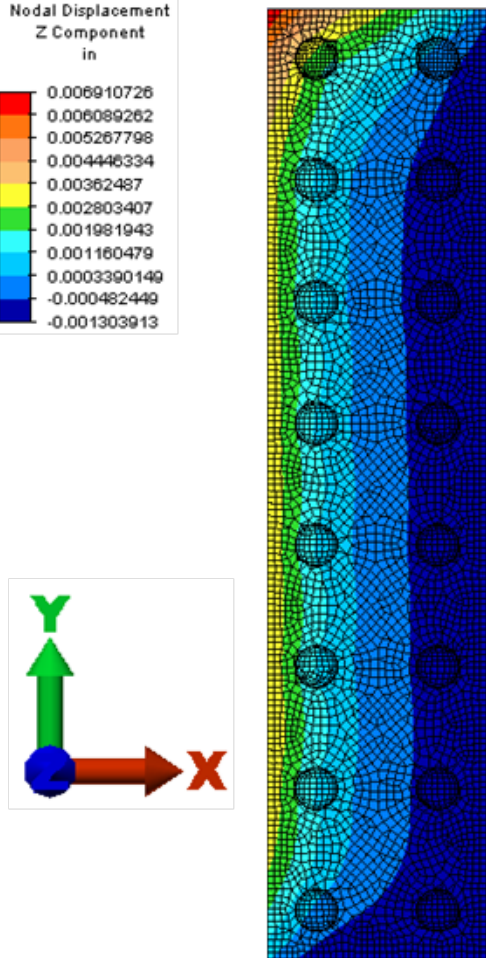

Nodal Displacement $Z$ Component
in

$\left[\begin{array}{l}0.02756424 \\ 0.02464512\end{array}\right.$

0.02172599

0.01880687

0.01588775

0.01296863
0.01004951

0.007130384

0.004211262

0.001282139
-0.001626983

Figure 9: Comparison between the Z-Displacement Contours of Idealized and Realistic FEM Models - 8x2 Joint Loaded with a $45^{\circ}$ Bending Moment 

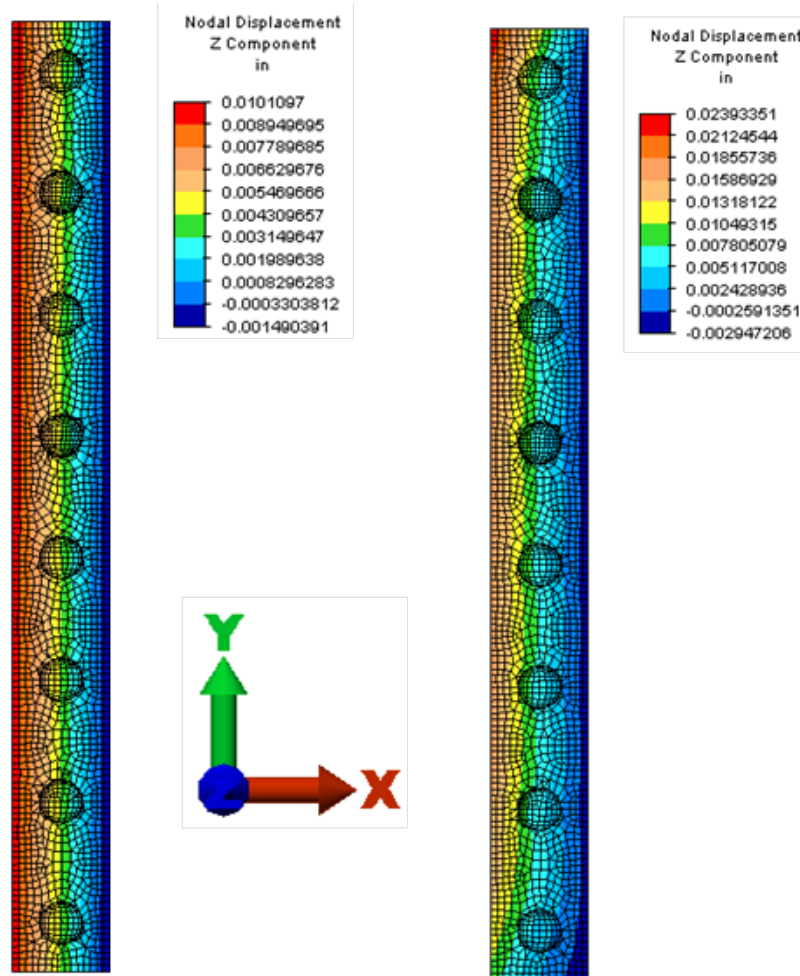

Idealized FEM Model

Max. Z-Displ. $=0.0101 "$
Realistic FEM Model

Max. Z-Displ. = 0.0239"

Figure 10: Comparison between the Z-Displacement Contours of Idealized and Realistic FEM Models - 8x1 Joint Loaded with a $45^{\circ}$ Moment

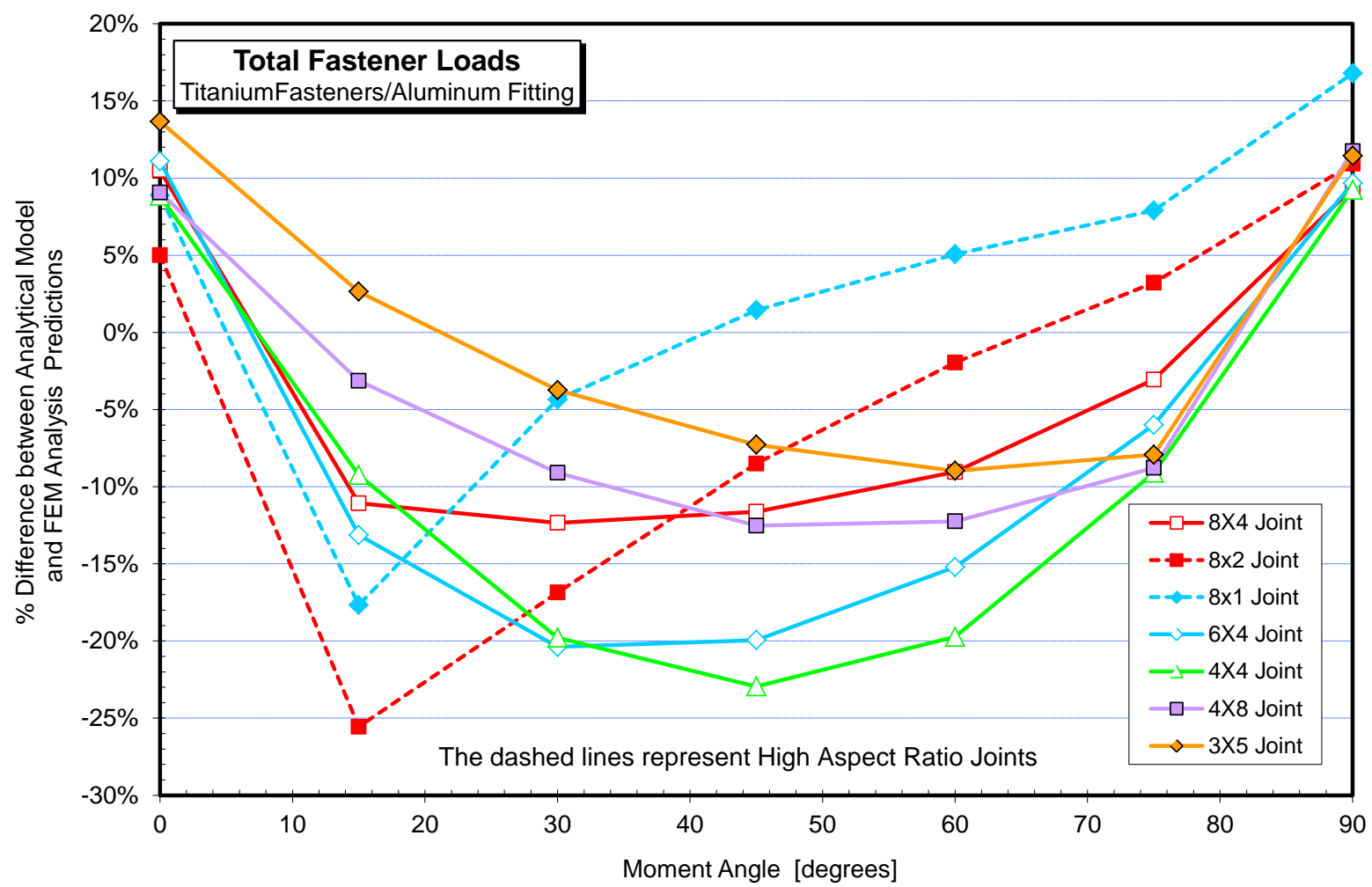

Figure 11: Percent Difference between Enhanced Analysis approach and Realistic FEM Analysis Predictions for Total Fastener Loads - All Joints 


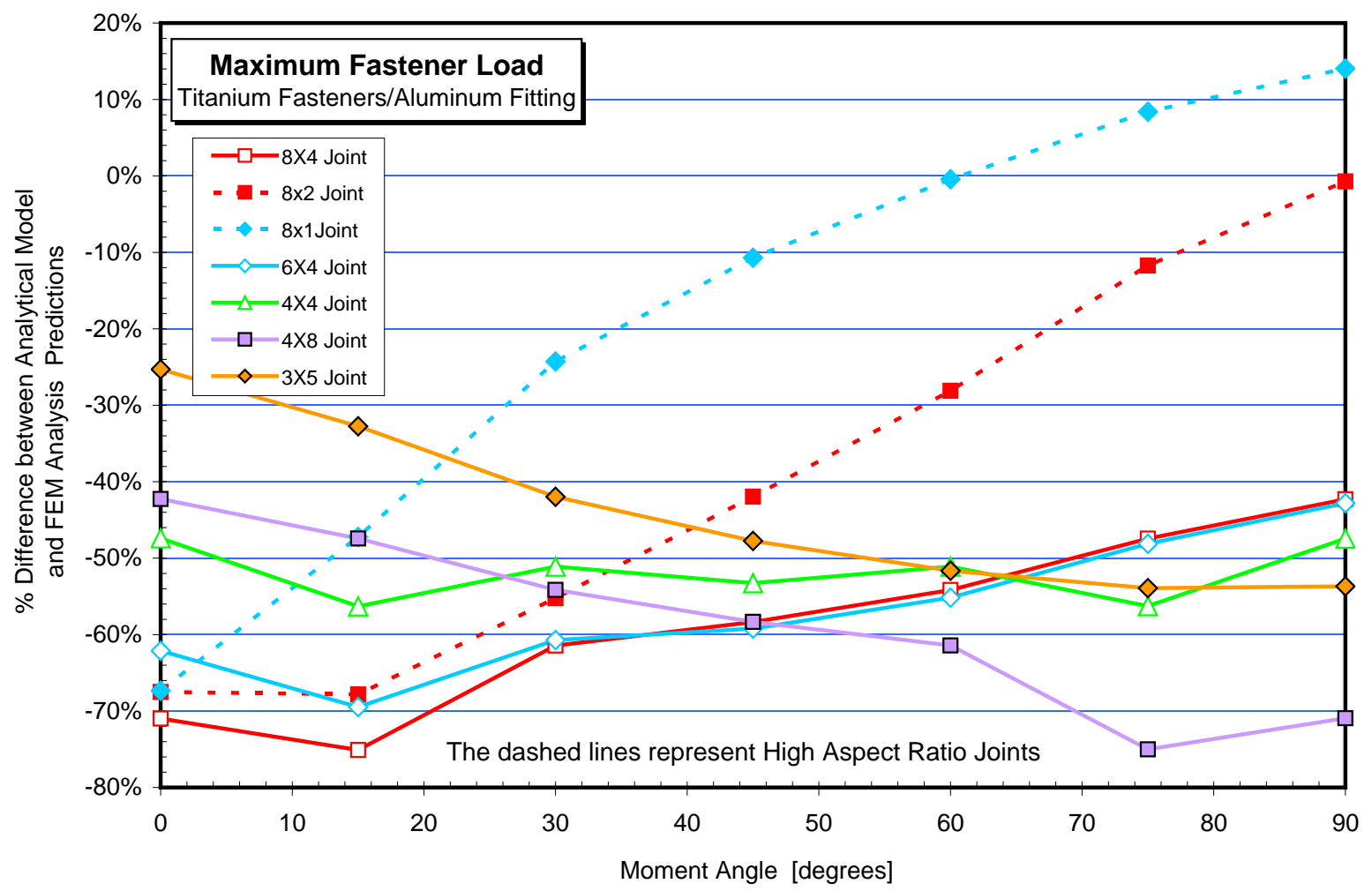

Figure 12: Percent Difference between Enhanced Analysis approach and Realistic FEM Analysis Predictions for Maximum Fastener Load - All Joints

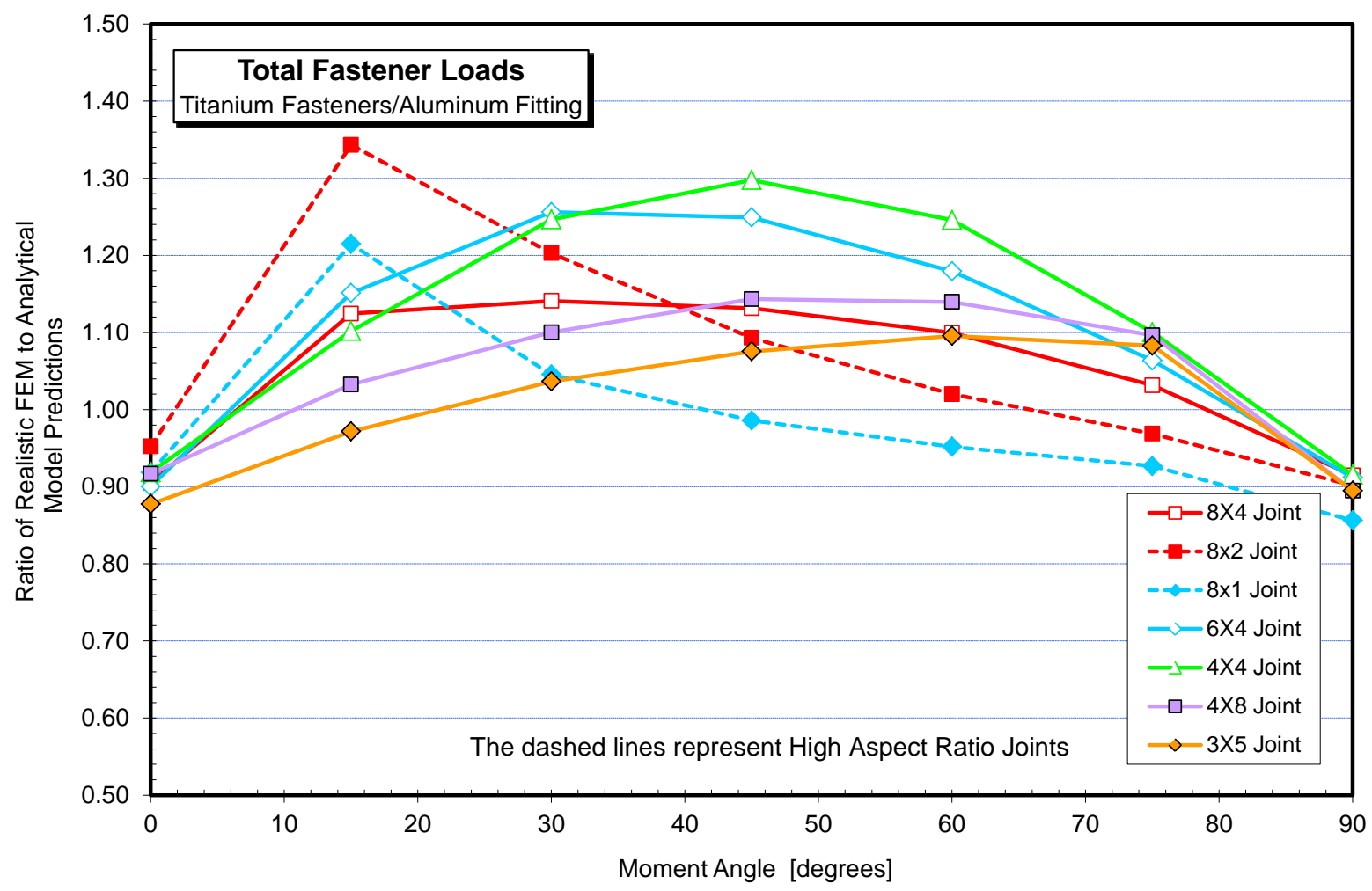

Figure 13: Ratio of Realistic FEM to Analysis approach Predictions - Total Fastener Loads 


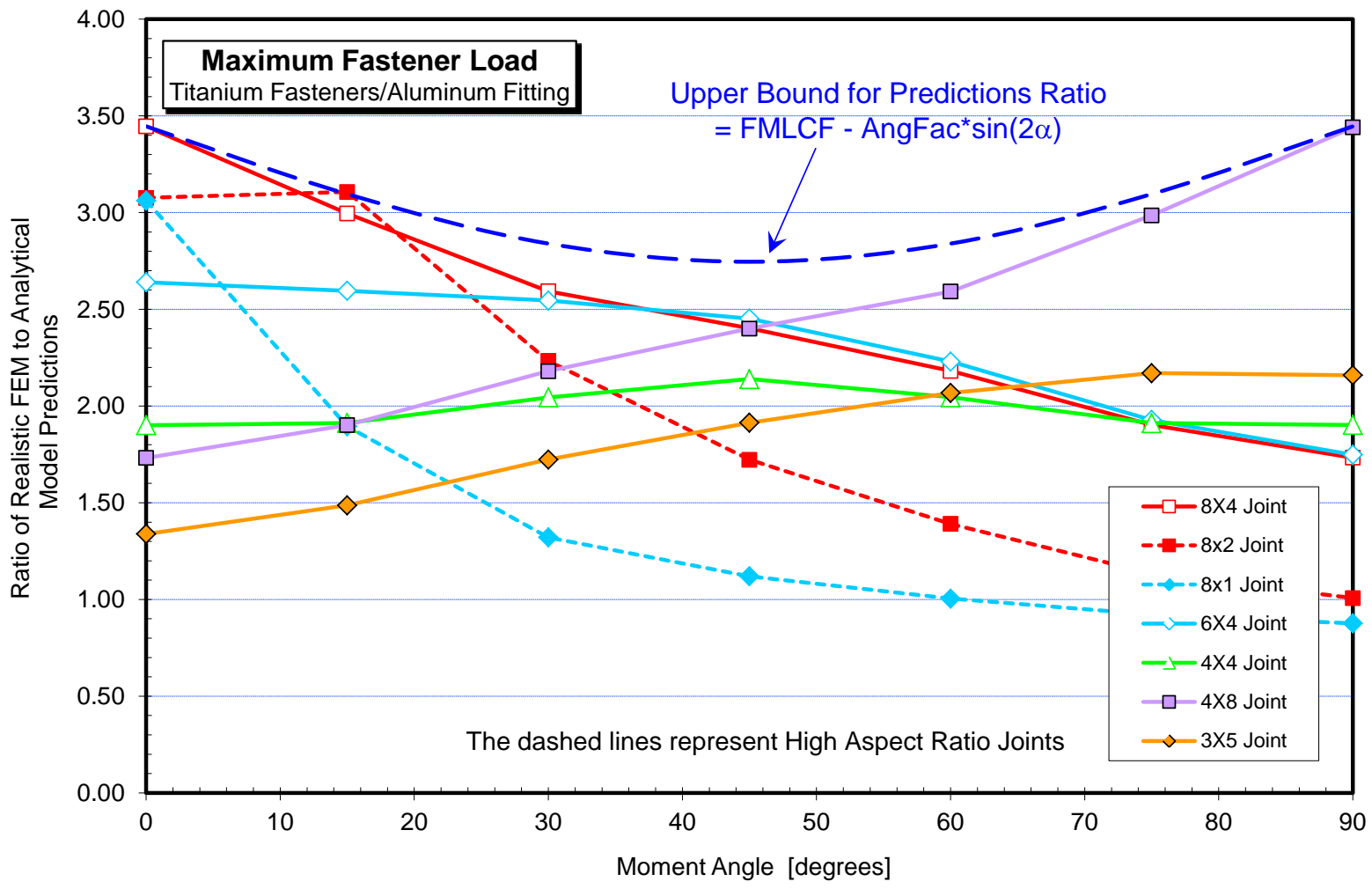

Figure 14: Ratio of Realistic FEM to Analysis approach Predictions - Maximum Fastener Load

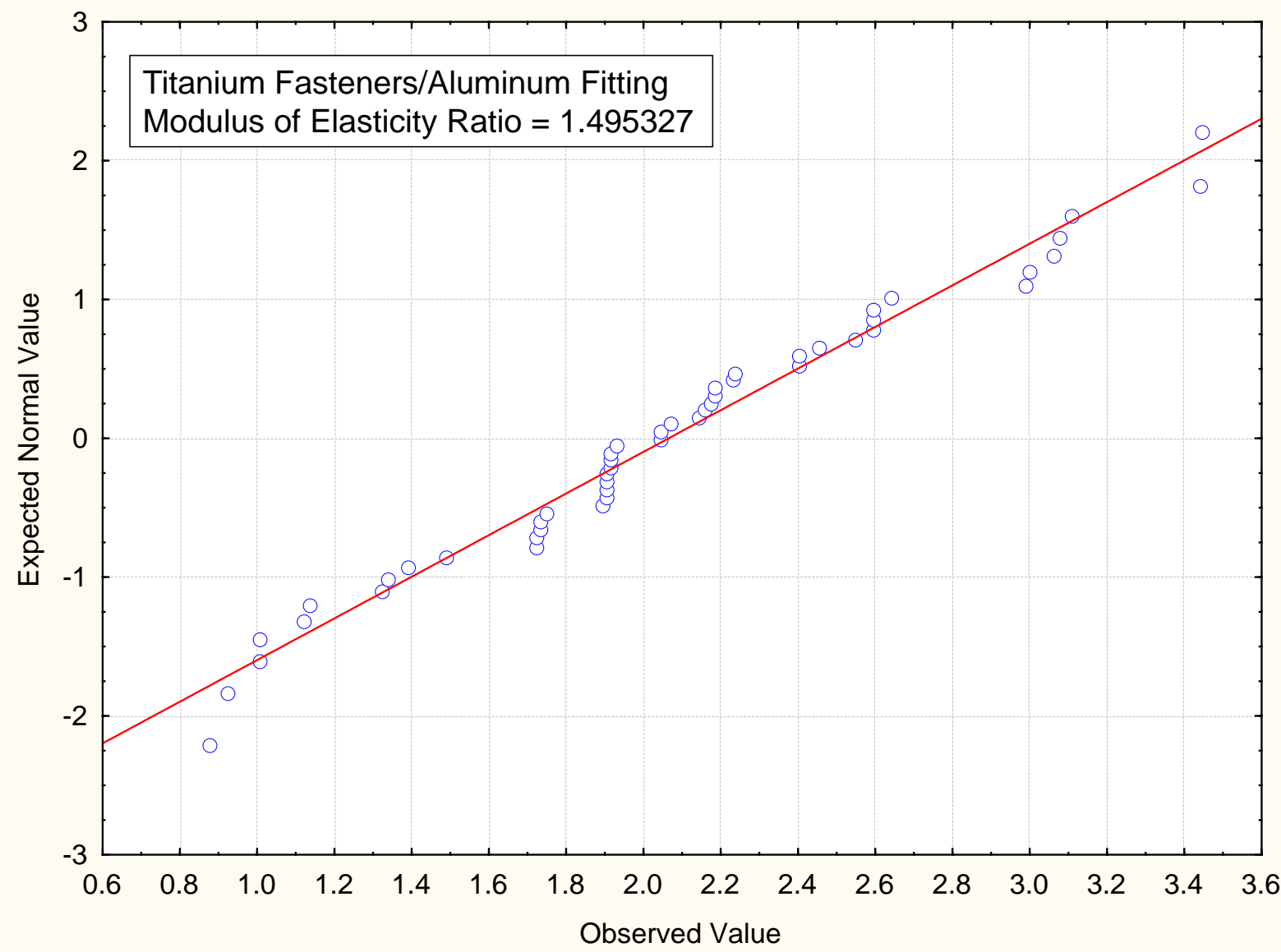

Figure 15: Normal Probability Plot of Fastener Maximum Load Correction Factors 


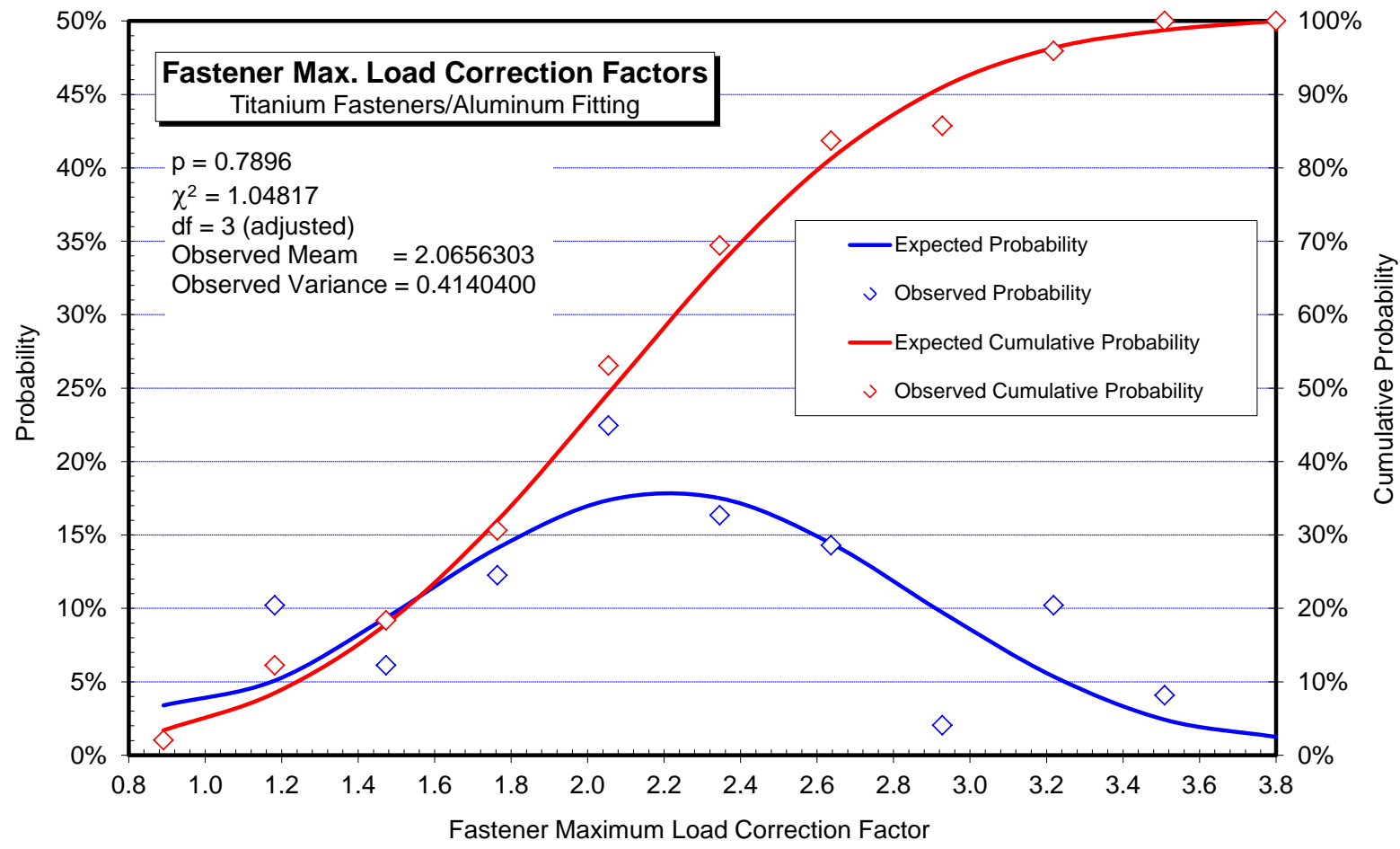

Figure 16: Observed and Expected Probabilities of Fitting a Normal Distribution to the Fastener Maximum Load Correction Factor and the Chi Test Results

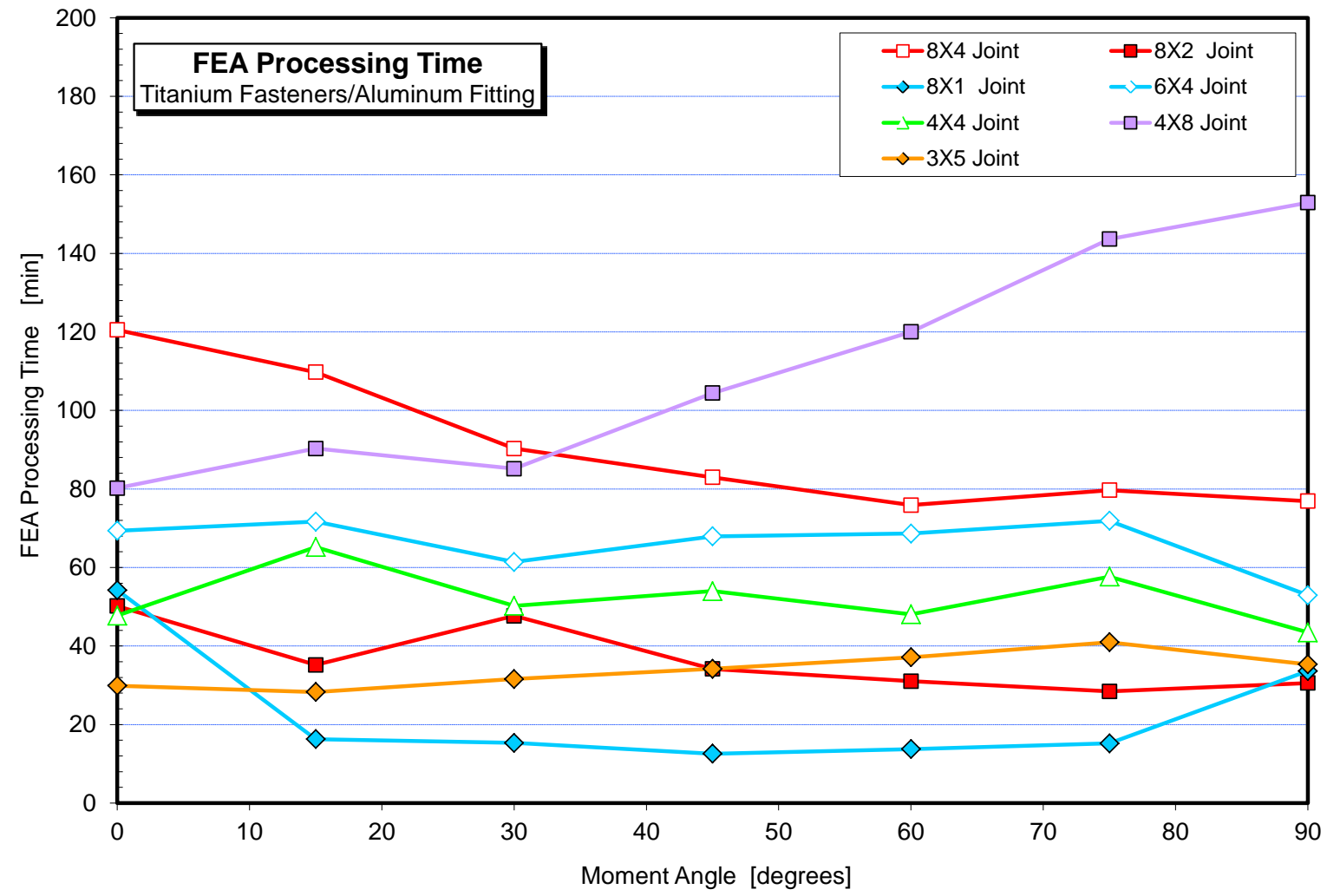

Figure 17: Processing Times of the Realistic FEM Models 


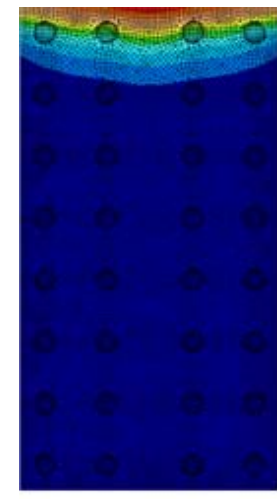

$\alpha=0^{\circ}$

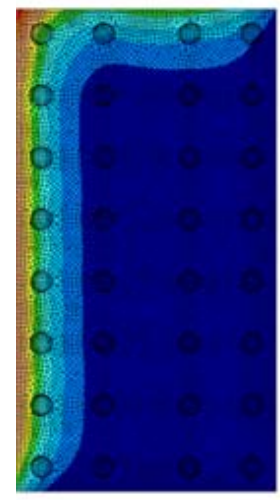

$\alpha=60^{\circ}$

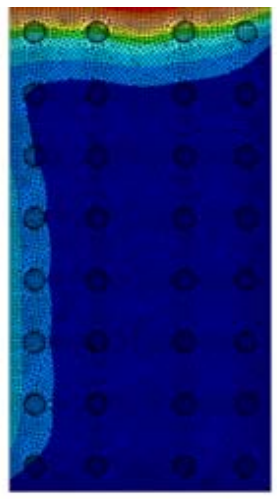

$\alpha=15^{\circ}$

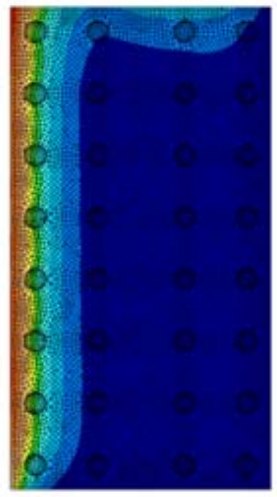

$\alpha=75^{\circ}$

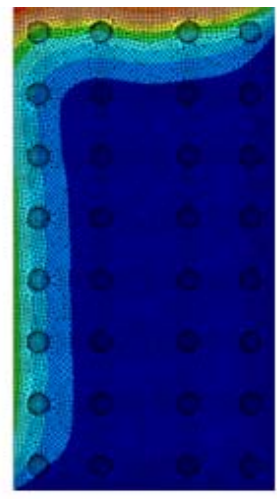

$\alpha=30^{\circ}$

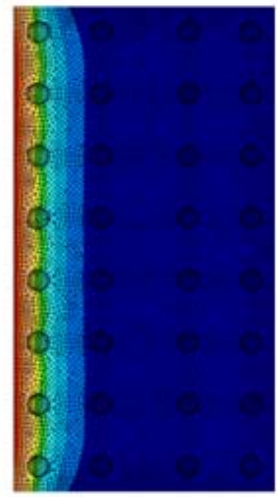

$\alpha=90^{\circ}$

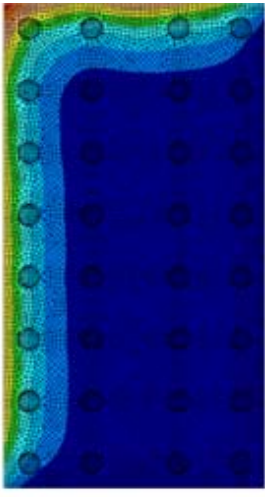

$\alpha=45^{\circ}$ Nodal Displacement $z$ Component

0.05747897

$-0.05153537$

$-0.04550176$

$-0.03964816$

$-0.03370456$

$-0.02776000$

$-0.02181735$

$-0.01587375$

0.000030147

0.003080545

Typical values. Actual values

may change from case to case

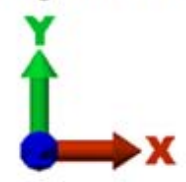

Figure 18: Realistic FEM Results Z-displacement Contours and Angle of Applied OutOf-Plane Bending Moment for the 8x4 Joint

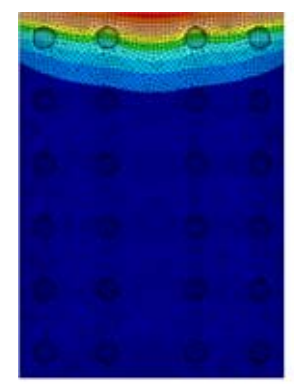

$\alpha=0^{\circ}$

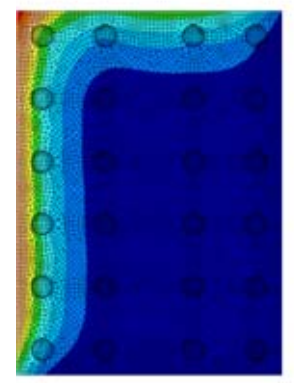

$\alpha=60^{\circ}$

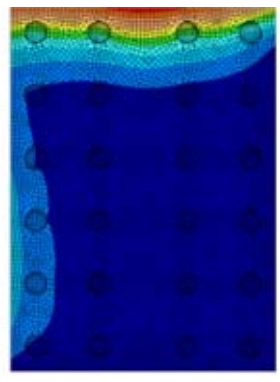

$\alpha=15^{\circ}$

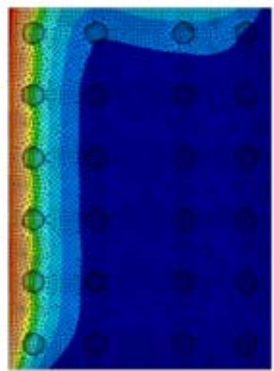

$\alpha=75^{\circ}$

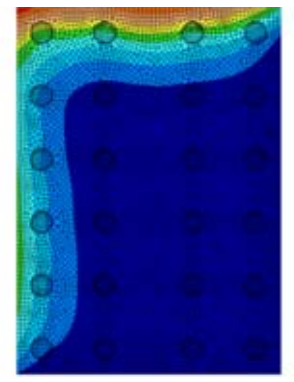

$\alpha=30^{\circ}$

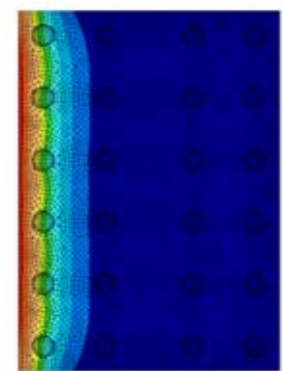

$\alpha=90^{\circ}$

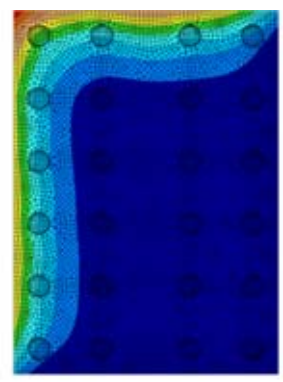

$$
\begin{aligned}
& \alpha=45^{\circ} \\
& \text { Nodal Displacement } \\
& Z \text { Component } \\
& \text { T } 0.04521098 \\
& 0.04053605 \\
& 0.03586003 \\
& 0.0311040 \\
& 0.02052287 \\
& \begin{array}{r}
0.02185084 \\
0.01717881
\end{array} \\
& \begin{array}{r}
0.01717881 \\
0.01250670
\end{array} \\
& \begin{array}{r}
0.01250670 \\
0.007834757
\end{array} \\
& \begin{array}{r}
0.007834757 \\
-0.003162720 \\
\hline
\end{array} \\
& \begin{array}{l}
0.00316272 \\
-0.0015093
\end{array}
\end{aligned}
$$

Typical values. Actual values may change from case to case

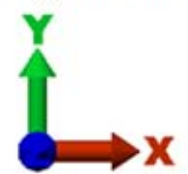

Figure 19: Realistic FEM Results Z-displacement Contours and Angle of Applied OutOf-Plane Bending Moment for the 6x4 Joint 


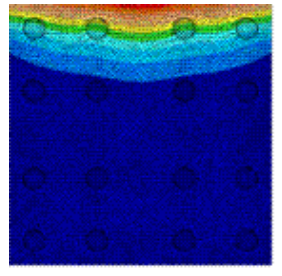

$\alpha=0^{\circ}$

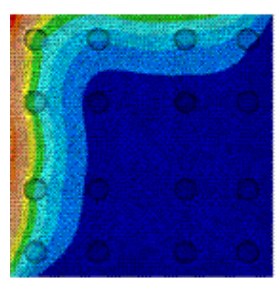

$\alpha=60^{\circ}$

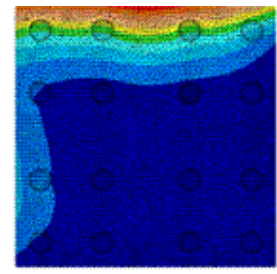

$\alpha=15^{\circ}$

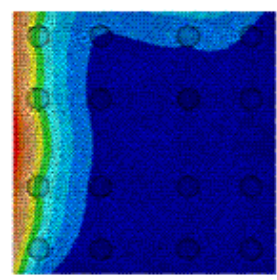

$\alpha=75^{\circ}$

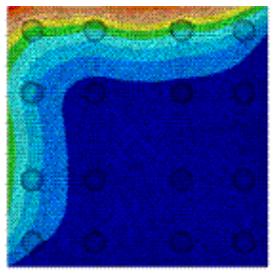

$\alpha=30^{\circ}$

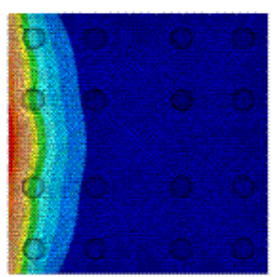

$\alpha=90^{\circ}$

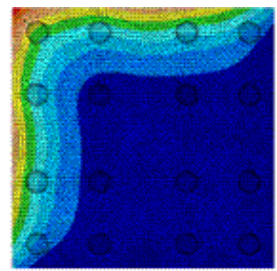

$\alpha=45^{\circ}$

Nodal Displacement
z Component

in

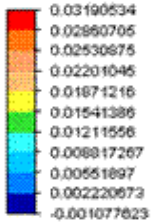

Typical values. Actual values may change from case to case

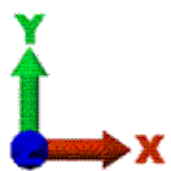

Figure 20: Realistic FEM Results Z-displacement Contours and Angle of Applied OutOf-Plane Bending Moment for the $4 x 4$ Joint

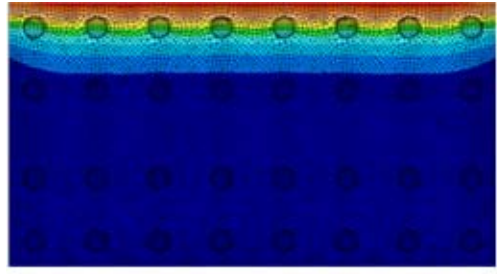

$\alpha=0^{\circ}$

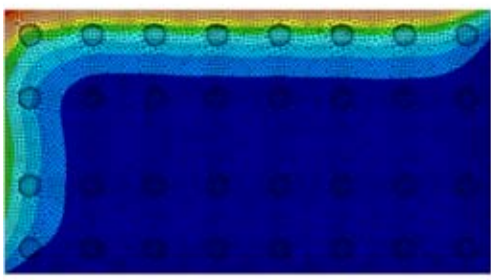

$\alpha=30^{\circ}$

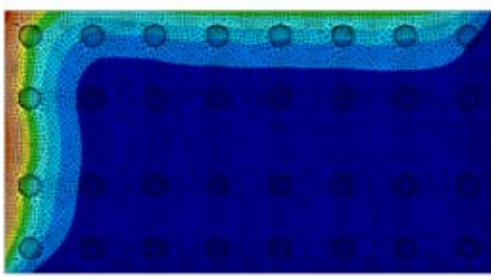

$\alpha=60^{\circ}$

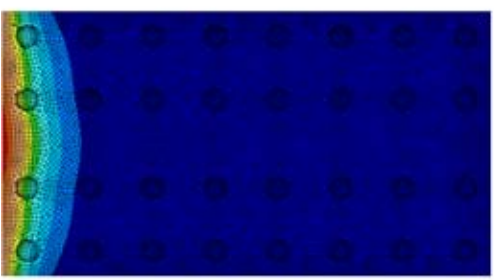

$\alpha=90^{\circ}$

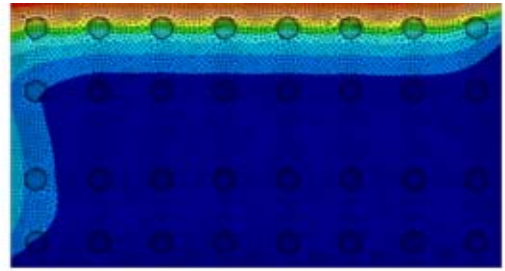

$\alpha=15^{\circ}$

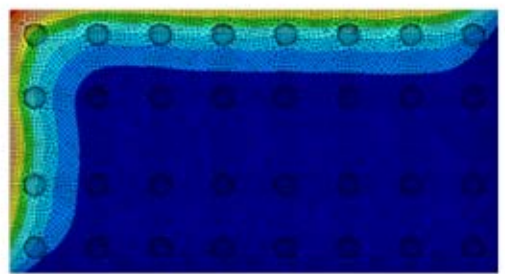

$\alpha=45^{\circ}$

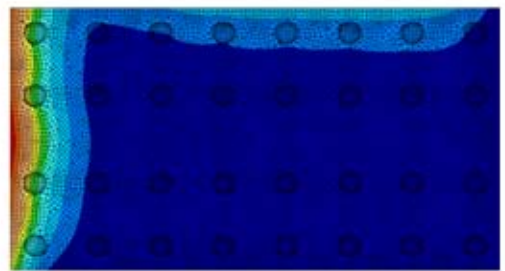

$\alpha=75^{\circ}$

Figure 21: Realistic FEM Results Z-displacement Contours and Angle of Applied OutOf-Plane Bending Moment for the $4 \times 8$ Joint 


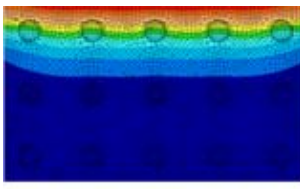

$\alpha=0^{\circ}$

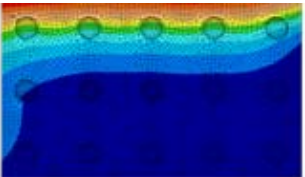

$\alpha=15^{\circ}$

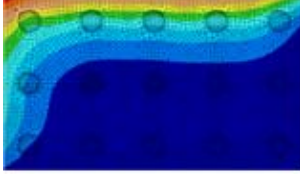

$\alpha=30^{\circ}$

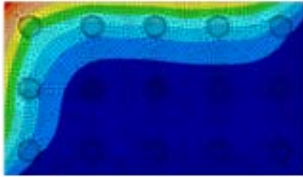

$\alpha=45^{\circ}$

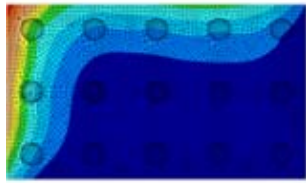

$\alpha=60^{\circ}$

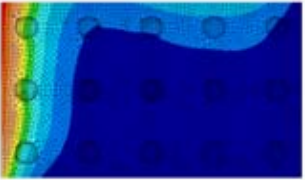

$\alpha=75^{\circ}$

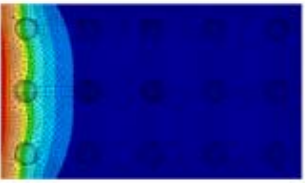

Nodal Displacement $z$ Componen 0.02152040
0.01028049
0.01705297 0.01705247 0.01401545 0.01287944 0.01034143
0.00810442 $-0.005687409$

Typical values. Actual values may change from case to case

$\alpha=90^{\circ}$

0.000093502859

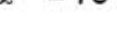

Figure 22: Realistic FEM Results Z-displacement Contours and Angle of Applied OutOf-Plane Bending Moment for the 3x5 Joint

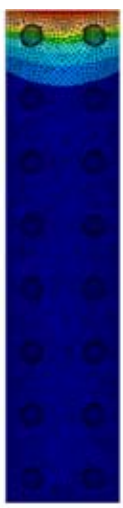

$\alpha=0^{\circ}$

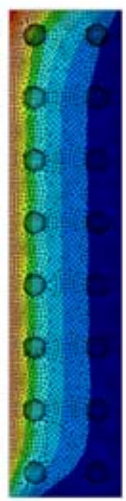

$\alpha=60^{\circ}$

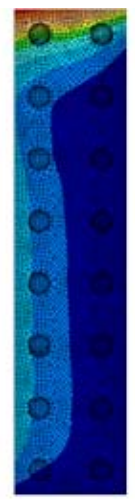

$\alpha=15^{\circ}$

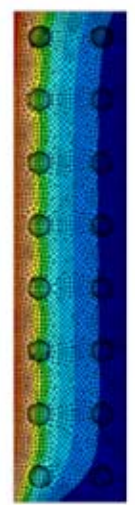

$\alpha=75^{\circ}$

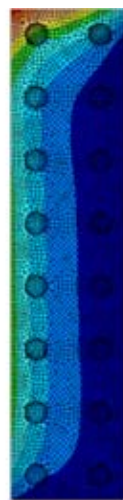

$\alpha=30^{\circ}$

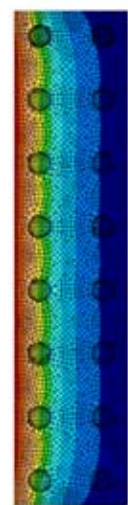

$\alpha=90^{\circ}$
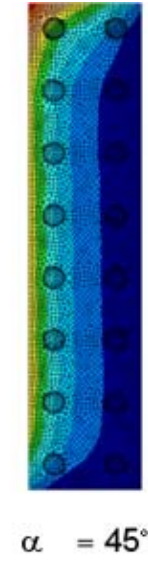

Nodal Displacement

$Z$ Component

0.05375315

0.0400711

0.03670705

0.0310280

0.0253429

$-0.01006009$

0.01397891

0.008206877

0.002814949

Typical values. Actual values may change from case to case

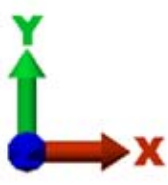

Figure 23: Realistic FEM Results Z-displacement Contours and Angle of Applied OutOf-Plane Bending Moment for the 8x2 Joint 

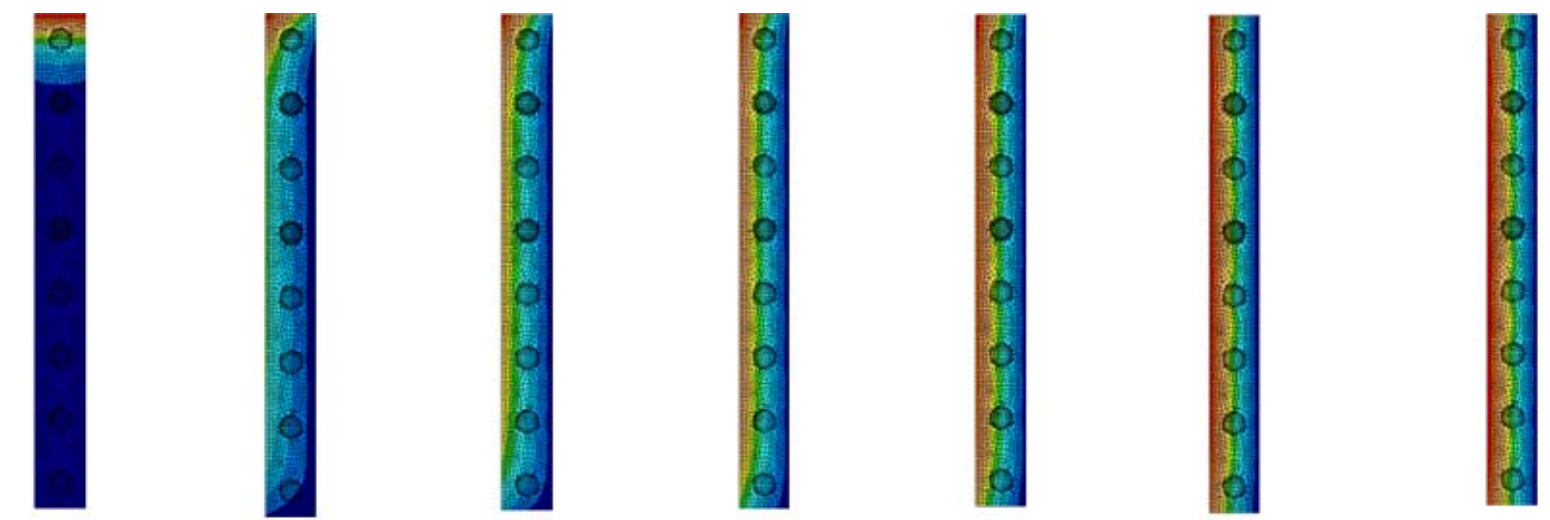

$\alpha=0^{\circ}$

$\alpha=15^{\circ}$

$\alpha=30^{\circ}$

$\alpha=45^{\circ}$

$\alpha=60^{\circ}$

$\alpha=75^{\circ}$

$\alpha=90^{\circ}$

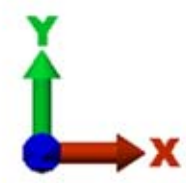

Typical values. Actual values may change from case to case

Nodal Displacement $z$ Comporent

in

0.0474014

$-0.04170328$

- 0.03012514

$-0.030457$

- 0.02478886

$-0.01912072$

0.01345258

0.007784435
0.002110294

0.002110204

Figure 24: Realistic FEM Results Z-displacement Contours and Angle of Applied OutOf-Plane Bending Moment for the 8x1 Joint 